\title{
CIÊNCIA, TECNOLOGIA, INOVAÇÃO E DESENVOLVIMENTO NO PROGRAMA DE EMPREENDEDORISMO DA UNIVERSIDADE TECNOLÓGICA FEDERAL DO PARANÁ
}

Josieli Soares dos Santos*

Edival Sebastião Teixeira**

Marcos Junior Marini***

\section{Resumo}

No Brasil, têm sido desenvolvidas políticas de apoio a processos de inovação tecnológica para empresas, com a finalidade de propiciar a estas melhores condições para que se mantenham saudáveis no mercado e melhorem seu potencial competitivo. É nesse contexto que se insere o Programa de Empreendedorismo e Inovação (Proem), desenvolvido na Universidade Tecnológica Federal do Paraná (UTFPR), campus Cornélio Procópio. O presente artigo resulta de pesquisa que analisou os modos pelos quais participantes desse programa concebem as relações existentes entre ciência, tecnologia, inovação e desenvolvimento. Para tanto, participaram voluntariamente da investigação 14 sujeitos que atuam no Proem, sendo eles gestores de empresas graduadas, gestores de empresas incubadas, gestores de empresas pré-incubadas e servidores da UTFPR. Os dados foram coletados mediante entrevista semiestruturada, cujo roteiro focava nos modos como os participantes concebem as referidas relações e as implicações sociais destas. A análise foi feita mediante interpretação das respostas dadas pelos sujeitos nas entrevistas. Os resultados obtidos indicam a presença de elementos do pensamento positivista. Foi possível verificar uma aproximação das concepções dos participantes com o modelo de desenvolvimento segundo o qual quanto mais se gera ciência, mais se gera tecnologia e, quanto mais tecnologia há, por consequência, mais se produz riqueza e bem-estar social - o qual, por sua vez, está na base da teoria schumpeteriana.

Palavras-chave: Ciência. Tecnologia. Inovação. Desenvolvimento. Empreendedorismo.

\footnotetext{
* Mestre em Desenvolvimento Regional pelo Programa de Pós-Graduação em Desenvolvimento Regional da UTFPR. Docente na Universidade Tecnológica Federal do Paraná (UTFPR).E-mail: josielisantos@utfpr.edu.br ** Doutor em Educação pela Universidade de São Paulo (USP). Docente do Programa de Pós-Graduação em Desenvolvimento Regional da UTFPR.E-mail: edival@utfpr.edu.br

*** Doutor em Tecnologia pela Universidade Tecnológica Federal do Paraná (UTFPR). Docente do Programa de Pós-Graduação em Desenvolvimento Regional da UTFPR. E-mail: marini@utfpr.edu.br
} 


\section{Introdução}

No Brasil, têm sido desenvolvidas políticas de apoio a processos de inovação tecnológica para empresas, com a finalidade de propiciar a estas melhores condições para que se mantenham saudáveis no mercado e melhorem seu potencial competitivo. Dentre essas políticas, destacam-se a Lei no 10.973, Lei da Inovação (BRASIL, 2004), e a Lei no 11.196/2005, Lei de Incentivos Fiscais à Inovação e à Exportação (BRASIL, 2005a). Além disso, órgãos vinculados ao Ministério da Ciência e Tecnologia, como a Financiadora de Estudos e Projetos e o Conselho Nacional de Desenvolvimento Científico e Tecnológico, vêm atuando como agentes de apoio para o desenvolvimento científico e tecnológico das empresas em geral. O sistema educacional, em especial as instituições de Ensino Técnico e Superior, públicas e privadas, também têm atuado nessa direção através de processos de interação entre academia e empresas.

Segundo Silveira e Bazzo (2009), dentre as diversas maneiras de se estimular o desenvolvimento de inovações tecnológicas existentes no Brasil, destacam-se as incubadoras de empresas de base tecnológica, as quais são criadas com a finalidade de acompanhar as transformações tecnológicas que têm ocorrido nos processos de trabalho, bem como servir de fontes estimuladoras para possibilidades de emprego e de renda. Esse tipo de organização tem o propósito de oferecer a empreendedores a oportunidade de participarem de programas de formação para a concepção de novos negócios ou para a assistência a negócios já existentes.

Conforme Medeiros (1992, p. 18), “uma das formas mais eficazes para promover o desenvolvimento tecnológico apoia-se na parceria pesquisa-empresa-governo". É necessário, no entanto, que se criem estratégias, no país, que superem as dificuldades e gerenciem a relação entre esses agentes para criar vantagens competitivas, nas empresas, por meio da inovação. Sendo assim, mercado e unidades produtivas constituem elos básicos da cadeia tecnológica, e as universidades e os institutos 
de pesquisas devem operar atentos às necessidades de mercado para agirem como força que impulsiona o setor produtivo, abrangendo, em seus projetos, as dimensões da educação, da ciência e da tecnologia.

É nesse contexto que se insere o Programa de Empreendedorismo e Inovação (Proem), desenvolvido na Universidade Tecnológica Federal do Paraná (UTFPR), campus Cornélio Procópio, desde 1997. O programa atua na formação da cultura empresarial e propicia espaços de desenvolvimento para projetos de empresas de base tecnológica. $\mathrm{Na}$ universidade, o programa se desenvolve através dos hotéis tecnológicos e de incubadoras de empresas, abrangendo da biotecnologia à robótica (UTFPR, 2015).

$\mathrm{Na}$ lei que transformou o Centro Federal de Educação Tecnológica do Paraná em Universidade Tecnológica Federal do Paraná, de outubro de 2005, a questão do desenvolvimento local e regional é bastante enfatizada como um dos princípios que regem a instituição. Da mesma forma, a lei ainda preconiza que esta tem por finalidade, dentre outras, prover a "integração da geração, disseminação e utilização do conhecimento para estimular o desenvolvimento socioeconômico local e regional" (BRASIL, 2005b). Nota-se, assim, que, em vários documentos institucionais atuais (UTFPR, 2009, 2014), bem como em vários discursos da comunidade universitária que circulam interna ou externamente à instituição, é recorrente a ênfase que se dá à UTFPR como importante agente de desenvolvimento regional.

Destaca-se, contudo, que os conceitos de ciência, de tecnologia, de inovação e de desenvolvimento são polissêmicos e, grosso modo, podem ser agrupados em duas tendências: uma tradicional, baseada na visão positivista, e uma que, neste artigo, é denominada crítica. As diversas correntes teóricas existentes tencionam entre si por defenderem pontos de vistas distintos quanto aos sentidos e as implicações de tais conceitos. Em estudo desenvolvido no campus de Pato Branco da UTFPR, por exemplo, Busato (2012) evidenciou o predomínio de uma visão economicista de desenvolvimento nos trabalhos realizados nesta. A autora pondera, entretanto, 
que a instituição, por estar inserida numa sociedade capitalista, sente os reflexos das contradições dessa sociedade, de modo que falar em desenvolvimento, em seu interior, pressupõe considerar o quanto a universidade tem sido influenciada e cobrada para dar conta das novas necessidades do capital.

$\mathrm{O}$ presente artigo resulta de pesquisa que analisou os modos pelos quais participantes do Proem do campus Cornélio Procópio da UTFPR concebem as relações existentes entre ciência, tecnologia, inovação e desenvolvimento. Participaram voluntariamente da investigação quatorze sujeitos que atuam no Proem, sendo eles um gestor de uma empresa graduada, cinco gestores de empresas incubadas, cinco gestores de empresas pré-incubadas e três servidores técnico-administrativos da UTFPR. Todos possuem formação superior concluída ou estão cursando-a. Quanto à área de formação, há predomínio das engenharias e das áreas de tecnologias computacionais, que contam com onze sujeitos. Dentre os demais, um participante tem formação em Marketing, outro em Educação Física e outro em Comunicação Social.

Os dados foram coletados mediante entrevista semiestruturada, cujo roteiro focava nos modos como os participantes concebem as relações entre ciência, tecnologia, inovação e desenvolvimento e as implicações sociais destas. As entrevistas foram gravadas e, posteriormente, transcritas de maneira literal, visando a facilitação da identificação e da organização dos dados. A análise foi feita mediante a proposta de interpretação qualitativa, a qual Minayo (1992) denomina de método hermenêutico-dialético, que se caracteriza pela análise da fala dos atores sociais situada em seu próprio contexto.

\section{Visão tradicional sobre ciência, tecnologia, inovação e desenvolvimento}

$\mathrm{Na}$ visão tradicional, a ciência é vista como uma ação objetiva, autônoma e neutra baseada no emprego de um código de racionalidade própria, alheia a qualquer tipo 
de racionalidade externa. Esse pensamento, oriundo do positivismo lógico, enfatiza a ciência e o método científico como única fonte do conhecimento, estabelecendo forte distinção entre fatos e valores.

Uma teoria econômica fortemente motivada pelo positivismo, surgida no início do século $\mathrm{XX}$ e que atrelou a inovação tecnológica ao desenvolvimento econômico, foi a de Schumpeter. De acordo com Costa (1997), a teoria shumpeteriana destacou o modelo dinâmico da economia, relacionando os períodos de prosperidade ao fato de que o empreendedor inovador, ao criar seus produtos, é imitado por inúmeros outros empreendedores não inovadores que investem recursos para produzir e imitar os bens ou serviços criados pelo empresário inovador. À medida que são introduzidas as inovações tecnológicas no mercado ou que ocorrem modificações nos produtos antigos e há uma absorção do seu consumo, "a taxa de crescimento da economia diminui [e] tem início um processo recessivo com a redução dos investimentos e a baixa a oferta de emprego" (COSTA, 1997, p. 12). Esse movimento de alternância entre prosperidade e recessão e a descontinuidade no aumento da produção é considerado por Schumpeter como um obstáculo periódico e transitório no curso natural de expansão da renda nacional, da renda per capita e do consumo.

Schumpeter (1997) vincula o conceito de inovação tecnológica ao sistema econômico. Para o autor, os avanços tecnológicos são regulados pelo mercado, e o objetivo da produção tecnológica é determinado pelo sistema econômico, pois a tecnologia só desenvolve métodos produtivos se houver demanda. Assim, é a conveniência que regula a produção tecnológica, assim como a econômica. A inovação é considerada, em sua perspectiva, como uma das responsáveis pelo alcance de lucros diferenciados pelas empresas, bem como por conquistas de poder competitivo. Logo, a inovação representaria o grande estímulo para o empreendedor na sua busca por mudanças. O empresário, em sua visão, passaria a ser o grande instigador do consumo, no processo econômico, 
iniciando um processo de mudança econômica em que os consumidores seriam educados por este e, "se necessário, são, por assim dizer, ensinados a querer coisas novas, ou coisas que diferem em um aspecto ou outro daquelas que tinham hábito de usar" (SCHUMPETER, 1997, p. 76).

Ainda na visão positivista, Tidd, Bessant e Pavitt (2008) destacam que a inovação é uma questão de conhecimento, integrante de um processo em que se criam novas possibilidades por meio da combinação de diferentes conjuntos de conhecimentos, os quais "podem vir na forma de conhecimentos sobre o que é tecnicamente possível ou de que configuração pode responder a uma necessidade articulada ou latente" (TIDD; BESSANT; PAVITT 2008, p. 35). Segundo os autores, os processos de gestão da inovação se desdobram sob condições de alta incerteza, transformando tais incertezas em conhecimento.

Segundo a Organização para Cooperação e Desenvolvimento Econômico (OCDE), foram verificadas, nas economias mais avançadas, a tendência a uma maior dependência de conhecimento, de informações e de altos níveis de competência e uma crescente necessidade de pronto acesso a tudo isso. Segundo essa organização, o conhecimento, em todas as suas formas, é crucial para o desenvolvimento econômico, de modo que as "nações que desenvolvem e gerenciam efetivamente seus ativos de conhecimento têm melhor desempenho que as outras", por isso, a "estrutura de políticas deve, portanto, dar ênfase à capacidade de inovação e criação de conhecimento nas economias" (OCDE, 2005, p. 31).

No Manual de Oslo (OCDE, 2005), explicita-se que, no nível macro, há um substancial conjunto de evidências de que a inovação é o fator dominante no crescimento econômico nacional e nos padrões do comércio internacional. No ambiente interno da empresa, no nível micro, a pesquisa e o desenvolvimento tecnológico $(\mathrm{P} \& \mathrm{D})$ é vista como o fator de maior capacidade de absorção e de utilização, pela empresa, não só de conhecimento tecnológico, mas de outros distintos novos conhecimentos. A empresa inovadora é determinada por características agrupadas em duas categorias principais de 
competências: as competências estratégicas, vinculadas à visão de longo prazo, à capacidade de visualização e de antecipação de tendências de mercado e à capacidade de processar e assimilar informações tecnológicas e econômicas; e as competências organizacionais, dispostas por meio do gerenciamento de riscos, da cooperação interna entre departamentos operacionais, da cooperação externa por meio de consultorias, do envolvimento corporativo no processo de mudanças e de investimentos nos recursos humanos, como em pesquisas de público, de clientes e de fornecedores (OCDE, 2005).

Schumpeter é citado no Manual de Oslo com relação a sua perspectiva em afirmar ser fundamental conhecer o porquê da mudança tecnológica e o porquê de as empresas inovarem. Segundo a OCDE (2005, p. 33), “a razão apresentada na obra de Schumpeter é que elas estão em busca de lucros: um novo dispositivo tecnológico traz alguma vantagem para o inovador". Por conseguinte, no manual da OCDE, defende-se explicitamente que "onde o conhecimento tecnológico tiver características de bem público, haverá uma falha nas forças de mercado que, não fora isso, poderiam motivar as empresas a inovar" (OCDE, 2005, p. 34).

Etzkowitz (2009), em seu modelo da Hélice Tripla, enfatiza que a interação universidade-empresa-governo é a chave para a inovação e para o crescimento de uma economia baseada no conhecimento. Nessa relação, a universidade atua como promotora das relações com empresas/indústrias setores produtores dos bens e serviços - e com o Governo - setor regulador e fomentador da atividade econômica - no intuito de produzir novos conhecimentos, suscitar a inovação tecnológica e fortalecer o desenvolvimento econômico. $\mathrm{Na}$ teoria do autor, ao governo cabe o compromisso de fornecer recursos, financiar pesquisas e estimular o empreendedorismo organizacional como incentivo à criação de novos negócios, trabalhando em conjunto com a universidade e com a indústria no fomento às ações de inovação. A configuração ideal para o modelo da Hélice Tríplice é aquela em que as três esferas interagem lateralmente, assumindo cada uma parcialmente o papel das outras. 
Por sua vez, Silva (2003) discute a questão da gestão da technology management. Segundo o autor, essa abordagem tem a ver com as mudanças organizacionais, com as transformações nas formas de produção, nas relações de trabalho, nas relações entre mercado e meio ambiente e, sobretudo, na forma como são desenvolvidas e utilizadas as tecnologias de produtos e os processos de produção. Todas essas mudanças decorreram de muitos fatores, com destaque para os movimentos de qualidade empreendidos pelas empresas japonesas a partir da década de 1960, os quais exerceram forte influência no setor industrial de todos os países, nos seus diversos âmbitos, da gestão organizacional à gestão da produção e do trabalho. A partir de então, as empresas ocidentais tiveram que se adaptar a esse novo formato organizacional, tendo em vista as diferenças entre as culturas ocidental e japonesa, mas, após um período de adaptações, no início da década de 1990, constata-se certo equilíbrio de produtividade e de qualidade entre as empresas influenciadas por esse cenário. Esse contexto acabou por induzir as empresas a outra dimensão de competitividade, relacionada à inovação em produtos, em processos e em tecnologia: "A inovação em produtos/tecnologia passa a ser então função de aspectos internos e externos à empresa, dentro de um meio ambiente externo dinâmico e de transformações" (SILVA, 2003, p. 51). Segundo o autor, dentro dessa complexidade de reformulação organizacional, as empresas que não se adaptaram a essa nova forma de gestão tiveram uma dupla missão, envolvendo simultaneamente a gestão da qualidade e a gestão da tecnologia como fatores de competitividade e de sobrevivência no mercado.

Em suma, as visões até aqui mencionadas são de matriz positivista e balizam todos os documentos que sustentam o Programa de Empreendedorismo do UTFPR.

\section{Visão crítica sobre ciência, tecnologia, inovação e desenvolvimento}

Kuhn (1989) é um dos autores que trata a ciência sob uma perspectiva que dá importância à dimensão social e ao 
seu enraizamento histórico. Segundo o autor, o progresso é um atributo óbvio para os campos da ciência e da tecnologia. No entanto, de modo algum ele é linear. Dessa maneira, o desenvolvimento científico e tecnológico não se baseia numa compreensão linear de que mais ciência gera mais tecnologia, contrariando-se, pois, a tese positivista.

Bazzo, Linsingen e Pereira (2003) criticam a perspectiva positivista pela qual é possível conceber a tecnologia como cadeia transmissora da melhoria social, pois, de fato, a ciência e a tecnologia não são formas autônomas da cultura, nem atividades neutras que, por si mesmas, levam ao desenvolvimento. Em outras palavras, nem ciência, nem tecnologia são autônomas em relação à história e à sociedade. Bourdieu (1983) também entende a ciência como produto do meio social, meio este que envolve relações de força, de interesse e de poder, o que impede, portanto, que a ciência seja pura e neutra. $\mathrm{O}$ autor compara o campo científico a um espaço de jogo, de luta concorrencial, que não proporciona concorrência perfeita das ideias: "O que está em jogo especificamente nessa luta é o monopólio da autoridade científica definida, de maneira inseparável, como capacidade técnica e poder social" (BORDIEU, 1983, p. 122). Essa luta, pela perspectiva de Santos (2006), sugere o estabelecimento da autorreflexidade proposta por autores que "têm vindo lutar por uma maior abertura epistêmica, no sentido de tornar visíveis campos do saber que o privilégio epistemológico da ciência tendeu a neutralizar, e mesmo ocultar, ao longo dos séculos" (SANTOS, 2006, p. 152). Para o autor, essa autorreflexidade induz um duplo questionamento: “[...] porque são todos os conhecimentos não científicos considerados locais, tradicionais, alternativos ou periféricos? Porque permanece a relação de dominação apesar de mudarem as ideologias que justificam (progresso, civilização, desenvolvimento, modernização, globalização, governação)?" (SANTOS, 2006, p.152) Há, portanto, uma dicotomia entre o científico e o não científico, que se apresenta de diversas formas, também dicotômicas: monocultural/multicultural; desenvolvido/subdesenvolvido; avançado/atrasado; moderno/ 
tradicional; global/local; etc. Para o autor, cada variável dessa revela uma dimensão da dominação.

Santos (2006) também defende que o conhecimento científico é de suma importância para a vida das sociedades contemporâneas, tornando-se uma forma privilegiada de conhecimento. Para o autor, existe o conhecimento em sociedade, e "quanto maior for o seu reconhecimento, maior será sua capacidade para conformar a sociedade, para conferir inteligibilidade ao seu presente e ao seu passado e dar sentido e direção ao seu futuro" (SANTOS, 2006, p. 13). Por outro lado, esse conhecimento, em suas múltiplas configurações, não está distribuído equitativamente na sociedade, de forma que se torna fundamental o debate, pois a ciência moderna assumiu sua inserção no mundo mais intensamente que qualquer outro tipo de conhecimento, uma vez que "propôs-se não apenas compreender o mundo ou explicá-lo, mas também transformá-lo"(SANTOS, 2006, p. 138). O autor afirma ainda que não é possível desvencilhar a investigação científica da sua relação com a inovação e com o desenvolvimento tecnológico, posto que "a inovação e o desenvolvimento tecnológico foram, em muitas situações do passado, inseparáveis da condução da própria investigação científica" (SANTOS, 2006, p. 147). A expressão "tecnociência", criada por Bruno Latour, foi proposta para assinalar a impossibilidade de diferenciação radical entre ciência e tecnologia e sua implicação mútua. Essa indissociabilidade é fator crucial para a compreensão das dinâmicas globais do conhecimento e das desigualdades, das tensões e dos conflitos que atravancam a ciência e a tecnologia (SANTOS, 2006).

Callon (2004), por sua vez, enfatiza a existência de profunda compatibilidade entre inovação e tradição, dizendo que "a inovação não destrói a tradição, ela se nutre dela e se enriquece com ela" (CALLON, 2004, p. 64). Para o autor, é impossível separar o novo e o moderno, pois, apesar de parecerem uma e a mesma coisa, ambos são diferentes na sua natureza e na sua aplicação. A inovação se apresenta no encontro de dois grandes processos de modernização, sendo 
que o primeiro deles é a entrada no mercado mundial e a adaptação à competição econômica, e o segundo, é o recurso cada vez maior a uma ciência considerada como fonte de progresso e de eficácia. Segundo o autor, "[...] não teríamos escolha. Para sobreviver seria preciso aceitar essas duas modernizações" (CALLON, 2004, p. 64), pois a inovação e a modernização são imposições não negociáveis feitas a todos. Isso quer dizer que a inovação, a um só tempo arma econômica e vontade de progresso, é figura que "estaria, de certo modo, no cerne do mundo moderno" (CALLON, 2004, p. 64).

Callon (2004) também critica o que chama de modelo linear ou de difusão de gestão, mediante o qual as empresas têm priorizado o treinamento de seus trabalhadores no sentido de capacitá-los para absorverem o mais rapidamente possível as inovações que chegam ao mercado produtivo. Esse modelo valoriza a qualidade das ideias, que dão origem à inovação. Em um padrão sequencial, a ideia passa aos primeiros desenhos e tentativas até chegar ao protótipo; em seguida, é realizado seu desenvolvimento, sua comercialização e, finalmente, sua validação ou rejeição, por parte do consumidor, à inovação.

Opondo-se ao modelo da difusão, há o modelo em rede, o qual valoriza a troca de informações e a discussão das ideias. Callon (2004, p. 71), destaca, a respeito dele, que,

à mercê das alianças que ela faz e desfaz, a inovação se transforma, se modifica permanentemente, é impossível apreender o que ela será, pois ela passa de mão em mão; cada um reage, adapta”. Assim, é se deslocando e se transformando que a inovação avança e se difunde e cria vínculos entre grupos, e ao circular através dos vínculos e relações que ela suscita e consolida - a inovação - cria o que se chama de rede sócio-técnica, a qual permite aos sujeitos "se veem partilhar um mesmo destino, pertencer ao mesmo mundo: seus interesses, suas ações, seus projetos foram progressivamente ajustados, coordenados.

Essa rede envolve tanto humanos quanto objetos, técnicas, máquinas, normas e valores, elementos a que, pelo fato de, com eles, integrarem a fabricação, a sociedade está, 
de certa maneira, apegada. Já que todos podem participar, os atores que se apoderam da inovação, nesse modelo, adquirem espaços de escolhas estratégicas, diferentemente do modelo da difusão, que negava a existências dessas margens de manobra (CALLON, 2004).

No que concerne ao conceito de tecnologia, Pinto (2005), outro autor da vertente crítica, apresenta quatro significados principais: a) a tecnologia como epistemologia da técnica; b) a tecnologia como equivalente à técnica, isto é, como termos intercambiáveis muito usuais no discurso habitual, coloquial e sem rigor; c) a tecnologia entendida como o conjunto de todas as técnicas que uma sociedade dispõe em qualquer fase histórica de seu desenvolvimento; e d) a tecnologia vista como importância capital, como a ideologia da técnica. Ao significar tecnologia como epistemologia da técnica, admite o autor a possibilidade de uma ciência da técnica, a tecnologia. A técnica configura-se, nesse contexto, como um produto da percepção humana que retorna ao mundo em forma de ação, de materialização em instrumentos e em máquinas e de entrega à transmissão cultural, pois "compreende-se [que] tenha obrigatoriamente de haver a ciência que o [referente] abrange e explora, dando em resultado um conjunto de formulações teóricas, recheadas de complexo e rico conteúdo epistemológico" (PINTO, 2005, p. 221). Nessa visão, a técnica é um ato produtivo e é definida como um ato humano, expressando a relação produtiva do homem com o mundo: "O domínio teórico da técnica pelo homem liberta-o da servidão prática à técnica, que vem sendo, crescentemente, o modo atual de vida pelo qual é definido e reconhecido" (PINTO, 2005, p. 223). A técnica deixa, assim, de ser apreendida na relação dos fenômenos frutos do comportamento da natureza para ser julgada em seu conceito lógico, segundo a maneira pela qual os homens organizam as relações sociais de produção (PINTO, 2005).

Por essa razão, Pinto (2005) critica concepções ingênuas da tecnologia, que propiciam o surgimento de conceitos alienantes como "explosão tecnológica", "tecnoestrutura", 
"cultura das massas", etc., os quais expressam meramente interesses sociais, criando uma ironia histórica que vitima os poucos pensadores honestos e trabalhadores. Em seus termos, "[...] é a consciência dos centros de poder político e técnico que se julga incumbida de definir a condição das massas humanas situadas em seu horizonte e de oferecer as soluções que devem remediar-lhes a trágica condição de vida” (PINTO, 2005, p. 227). Para o autor, somente aquele que considera determinante do seu pensamento o estado real de existência da humanidade, em totalidade, pode ser considerado um pensador crítico.

A noção de "explosão tecnológica" de que fala Latour (1994) tem sido ingenuamente empregada e se apresenta como uma deficiência de percepção de mundo que reside na ausência de sensibilidade histórica. $\mathrm{Na}$ verdade, a humanidade sempre acreditou, em cada momento, estar vivendo uma fase de esplendor, e em cada um deles houve uma "explosão tecnológica" - para utilizar a expressão de Latour - que, nos tempos atuais, já não mais emociona, por terem perdido, com o passar do tempo, os ecos dos abalos sociais, emocionais e ideológicos produzidos (PINTO, 2005). Atualmente, criou-se "um estereótipo verbal aplicado agora a qualquer propósito e com plena irresponsabilidade, o que vem confirmar [...], o maravilhamento do homem diante de suas criações" (PINTO, 2005, p. 236). Porém, só pode ser verídica a compreensão da tecnologia quando fundada sobre a noção da historicidade constitutiva do homem, e fatidicamente, do trabalho (PINTO, 2005).

Quanto ao conceito de desenvolvimento, a visão crítica rebate a ideia de que este consiste num processo linear e focado no crescimento econômico. Essa visão aceita a importância do esforço em promover o desenvolvimento por meio da industrialização e do crescimento econômico. Contudo, ainda que esse crescimento seja um requisito importante para a diminuição da pobreza e para a construção de um padrão de vida digno, ele não é suficiente para obtê-los. Por essa razão, Furtado (1974, p. 75) critica esse modelo de desenvolvimento, classificando-o como um mito que acabou desviando a 
atenção da "tarefa básica de identificação das necessidades fundamentais da coletividade e das possibilidades que abrem os avanços da ciência" para concentrá-la "em objetivos abstratos como são os investimentos, as exportações e o crescimento".

De acordo com Marini e Silva (2012), a visão de desenvolvimento ganha dimensões mais abrangentes que a do viés economicista, a partir da década de 1970, com as discussões em torno da harmonização do crescimento econômico com a preservação do meio ambiente. Nesse sentido, Sachs (2004) apresenta uma contribuição a essas discussões, partindo de uma análise da história do desenvolvimento, incorporando, como afirma o autor, "experiências positivas e negativas, refletindo as mudanças nas configurações políticas e as modas intelectuais" (SACHS, 2004, p. 25), concluindo que as discussões acerca dessa temática contribuíram para o refinamento do conceito, "porém contrastam com o sombrio histórico do desenvolvimento existente em muitas partes do mundo" (SACHS, 2004, p. 25).

Sachs olha com desconfiança o avanço dessas discussões, em termos de resultados práticos, e coloca para apreciação a "necessidade de se revisitar a ideia de desenvolvimento, com vistas a torná-lo mais operacional, enquanto se reafirma, mais do que nunca, a sua centralidade" (SACHS, 2004, p. 25). Nessa perspectiva, o desenvolvimento se torna multidimensional e seus objetivos são sempre sociais e éticos, contendo um compromisso ambiental explícito com as gerações futuras. Para o autor, o melhor entendimento do significado de desenvolvimento implica tomá-lo como includente, sustentável e sustentado. Entende-se "includente" quando "o desenvolvimento pode ser redefinido em termos da universalização e do exercício efetivo de todos os direitos humanos - políticos, civis e cívicos, econômicos, sociais e culturais, bem como direitos coletivos ao desenvolvimento, ao ambiente, etc." (SACHS, 2004, p. 37). O adjetivo "sustentável" se refere à condicionalidade ambiental, enquanto "sustentado" se refere à permanência do processo de desenvolvimento, não consistindo no mesmo que crescimento material. $\mathrm{O}$ autor 
conceitua o desenvolvimento, incluindo, na sua definição, três espécies de direitos humanos: direitos políticos civis e cívicos; direitos econômicos, sociais e culturais, que inclui o direito ao trabalho digno; e os direitos coletivos ao meio ambiente e ao desenvolvimento. Além disso, o conceito de desenvolvimento deve conter, para além da dimensão da sustentabilidade ambiental, a dimensão da sustentabilidade social (SACHS, 2004).

Por sua vez, Amartya Sen (2010) sugere uma análise normativa explícita para avaliar o processo de desenvolvimento, enfatizando-o igualmente como um fenômeno multidimensional que vai além da variável renda. Desse modo, para o autor, o desenvolvimento pode ser visto como um processo de expansão das liberdades reais que as pessoas desfrutam. Esse enfoque nas liberdades humanas contrasta com visões mais restritas de desenvolvimento, baseadas puramente no crescimento do PIB, no aumento de renda das pessoas e das famílias, na industrialização, na modernização social e nos avanços tecnológicos. Obviamente, esses aspectos compõem um meio muito importante de expansão das liberdades desfrutadas pela sociedade, mas o desenvolvimento não se restringe a eles.

A questão de que o mundo tem passado por mudanças com avanços notáveis, que excedem a esfera econômica, é considerada por Sen (2010). Em sua perspectiva, em decorrência da democratização política, direitos humanos estão sendo preservados e defendidos e conquistas como o aumento da expectativa de vida humana e os avanços tecnológicos, que estreitam as relações entre países e promovem o livre comércio internacional, entre outras consequências, são questões que assinalam positivamente a sociedade. No entanto, o mundo vive igualmente num contexto de privação. Problemas antigos permanecem, novos surgem e a pobreza persiste, impedindo que necessidades primordiais do ser humano sejam satisfeitas. Também cresce a violência, a fome coletiva se dissemina, ocorre ampla negligência diante das necessidades dos mais frágeis (mulheres, crianças e idosos) e as catástrofes ambientais 
emergem cada vez mais agravadas, de forma que as ameaças à sustentabilidade da vida econômica e social são uma constante (SEN, 2010).

Diante desse cenário, combater esses problemas é uma parte central do processo de desenvolvimento, por isso Sen (2010) propõe que é preciso reconhecer o papel das diferentes formas de liberdade na ação contra esses infortúnios. Há, entretanto, uma complementaridade entre a condição de agente individual e as disposições sociais que torna imprescindível reconhecer a simultaneidade central da liberdade individual e da força das influências sociais sobre o grau e o alcance da liberdade individual. Para combate aos problemas a serem enfrentados, é necessário considerar a liberdade individual como um comprometimento social.

$\mathrm{Na}$ abordagem seniana, a expansão da liberdade é vista como o principal fim e o principal meio do desenvolvimento. Assim, para o autor, o desenvolvimento consiste na eliminação de privações de liberdade, que limitam as escolhas e as oportunidades das pessoas de exercer sua condição de agente. Sua teoria reforça a necessidade de uma análise integrada das atividades econômicas, sociais e políticas, constituindo uma multiplicidade de instituições e muitas condições de agente relacionadas de forma interativa. Ela se concentra, pois, nos papéis e nas inter-relações entre liberdades instrumentais cruciais, incluindo-se oportunidades econômicas, liberdades políticas, facilidades sociais, garantias de transparência e segurança protetora (SEN, 2010).

Assim, considera-se a abordagem das capacitações um enfoque ímpar do desenvolvimento, pela qual a liberdade é um componente substantivo básico para os indivíduos. Para Sen (2010), a ação contra a pobreza deve ser constituída mediante a garantia e a ampliação das liberdades individuais, uma vez que essas liberdades alargam as capacitações das pessoas. Nessa ótica, a pobreza é entendida como a carência absoluta de algumas capacitações básicas, necessárias ao bem-estar, este particularmente multidimensional sob essa perspectiva. 


\section{Resumindo e comparando as duas visões}

Em suma, na visão tradicional, a ciência é considerada objetiva, autônoma e neutra, desenvolvendo-se linearmente, de modo que mais ciência gera mais tecnologia, e mais tecnologia gera mais riqueza, que se traduz em bem-estar social ou, em outras palavras, em desenvolvimento. Por sua vez, a visão crítica valoriza a dimensão social e o enraizamento histórico da ciência, tratando-a como produto do meio social, que envolve relações de força, de interesses e de poder, não sendo, portanto, neutra.

No que concerne ao conceito de tecnologia, a visão tradicional a concebe como a responsável pela expansão econômica, posto que desenvolve os métodos produtivos necessários para tanto, enquanto, na visão crítica, a tecnologia é vista como um produto inerentemente social e histórico. Quanto ao conceito de inovação, a visão tradicional concebe-a como baseada no conhecimento e, portanto, como um fator dominante no crescimento econômico, sendo, por isso, considerada o motor da competitividade mercadológica e como reguladora do mercado econômico e de consumo, bem como do alcance dos lucros empresariais; na visão crítica, a inovação é concebida como processo ou produto inerentemente social, vinculado a interesses e ações comuns, que demandam esforços coletivos na consolidação das ideias científicas e dos artefatos tecnológicos na busca pelo progresso humano e social, envolvendo valores morais, políticos, culturais, ambientais, religiosos e econômicos. Por fim, no que diz respeito ao conceito de desenvolvimento, pela visão tradicional, este está relacionado com o crescimento da economia traduzido em termos de Produto Interno Bruto (PIB), tendo a ver, portanto, com o crescimento estimulado pela competitividade das empresas na economia globalizada; na visão crítica, por sua vez, trata-se de um fenômeno multidimensional, que leva em conta as ideias de sustentabilidade, de inclusão e de expansão das liberdades individuais para além da questão meramente econômica. 


\section{A visão dos participantes da pesquisa sobre as relações entre ciência, tecnologia, inovação e desenvolvimento}

No que concerne à relação entre ciência, tecnologia, inovação e desenvolvimento, primeiramente, os participantes da pesquisa foram perguntados sobre como veem a relação entre ciência, tecnologia e sociedade. As respostas obtidas indicam que, de forma geral, essa relação é tida com muito positiva e importante. Não obstante, parte dos sujeitos afirma que o contexto científico-tecnológico - representado pela universidade, na visão deles - não tem sido capaz de corresponder às demandas da sociedade, e, via de regra, atribui parte desse problema ao fato de que a universidade não tem sido capaz de desenvolver mecanismos adequados de comunicação. Para um dos participantes, que disse que "há um desnível entre o que a sociedade precisa e o que a instituição oferece, pela falta de comunicação" (informação verbal), a universidade não tem sido eficaz no fornecimento de pessoal técnico apto a entrar imediatamente no mercado de trabalho, de modo que as empresas ainda precisam dar treinamento para os novos contratados. Para outros participantes, além dos problemas de comunicação entre universidade e sociedade, há a questão do descompasso entre a educação básica e a superior, no sentido de que "a tecnologia tem que ser discutida em nossas escolas, no ensino base, fundamental, tem que ter disciplinas que possam focar essa questão da inovação, incutir nessa nova geração que isso é importante" (informação verbal). Para esse participante, o empreendedorismo é uma das "ferramentas" para levar os jovens à compreensão da importância da ciência e da tecnologia, e que, se as pessoas não tiverem uma base de inovação e de tecnologia, não poderão ter sucesso.

Contudo, embora possa ser observado que vários participantes consideram importante a relação entre ciência, tecnologia - leia-se universidade - e sociedade, e que tal relação não tem sido profícua, seja por problemas de comunicação, seja por falta de boa base escolar dos jovens que chegam na academia, em nenhum momento de suas falas eles especificam quais seriam as demandas tecnológicas da sociedade. 
Para outro grupo de participantes, é a sociedade - percebida, em geral, como "o mercado" - que não está preparada para receber o conhecimento científico-tecnológico produzido pela universidade. Nesse sentido, por exemplo, um dos entrevistados afirmou que tanto a incubadora quanto a universidade formam "mão-de-obra muito interessante nessa área de tecnologia e ciência,e até inovação, mas talvez o mercado não esteja tão apto a receber essa mão-de-obra" (informação verbal). Nesse sentido, como afirma outro entrevistado, são os empresários que não estão preparados para administrarem seus negócios, devido a deficiências na formação. Além disso, ele defende que, muitas vezes, a "sociedade não consegue utilizar em sua plenitude" a ciência e tecnologia disponíveis "por uma deficiência cultural e educacional” (informação verbal).

Nas entrevistas, foram recorrentes as manifestações quanto às falhas na comunicação entre universidade e sociedade. Segundo os participantes, aquela tem sido deficiente na divulgação das tecnologias e inovações que produz, ao passo que esta está "muito acostumada com certos conceitos que não necessariamente são as últimas tendências tecnológicas" (informação verbal), de modo que é preciso divulgação para se "colocar no mercado algo que seja fora do comum” (informação verbal).

Apesar de vários respondentes tenham mencionado possíveis deficiências na comunicação entre universidade e sociedade, demonstrando que estão atentos à necessária interação entre ambas, como se poderia supor desde um ponto de vista crítico, no fundo, o que mais parece os preocupar é uma questão mercadológica. De fato, em muitas passagens das entrevistas, os termos "sociedade" e "mercado" aparecem intercambiáveis nas falas dos participantes. Manifestação explícita nesse sentido foi a de um entrevistado em específico, para quem o Proem é muito voltado para a sociedade, pois, para adentrar o programa, o candidato "tem que mostrar que tem uma ideia inovadora e que tem um mercado, que vai ajudar alguém, que alguém vai ter um interesse, que vai facilitar a vida de alguém" (informação verbal). Ainda 
relativo a essa questão, outro entrevistado, que é um dos gestores do Proem, valoriza a facilidade da incubadora em trazer a comunidade para dentro da universidade, e, assim, "aproveitar essa aproximação para a geração de novos negócios e o desenvolvimento regional” (informação verbal). Sob a perspectiva do entrevistado, essa relação da universidade/ sociedade se dá no intuito de desenvolver novos negócios, e assim, parece dizer que o desenvolvimento regional somente acontecerá com o empreendedorismo baseado na inovação tecnológica, aproximando-se, dessa forma, à visão tradicional de que a inovação tecnológica é a grande estimuladora do comportamento empreendedor e da consequente busca por mudanças, como considera Schumpeter (1997).

No que diz respeito às relações entre inovação e desenvolvimento, em várias entrevistas, observa-se uma visão que vincula a inovação ao conhecimento a partir de um viés econômico, como a defendida por autores como a OCDE (2005) e Tidd, Bessant e Pavitt (2008). Nos depoimentos de vários entrevistados, transparece que o desenvolvimento humano está relacionado à questão cultural e educacional, mas volta-se para o ambiente mercadológico, pois a pessoa necessita buscar seu autodesenvolvimento para adequarse ao mercado. Nesse sentido, um dos entrevistados afirma que a inovação afeta "a questão econômica por motivos da produtividade, diminuição de gasto, aumento da qualidade de vida do trabalhador, necessidade de redução de custos pela competitividade" (informação verbal).

A fala de outro entrevistado atrela o avanço da ciência e da tecnologia às transformações sociais que conduziram à globalização, às mudanças econômicas e de mercado e ao consequente aumento da competitividade. Porém, o que poderia parecer uma aproximação ao pensamento crítico, acaba de fato se inspirando nos trabalhos de Schumpeter (1997), de Silva (2003) e da OCDE (2005). Com efeito, se esse participante da pesquisa, por um lado, afirmou que "a tecnologia foi fundamental na globalização, porque hoje se tem uma comunicação rápida entre pessoas de vários lugares 
do mundo" (informação verbal), por outro, concluiu seu raciocínio realçando o poder que a tecnologia confere aos competidores no mercado por conta das possibilidades que a atual velocidade nas comunicações aporta. Assim, por mais que o aspecto social apareça nas falas desses entrevistados, o mesmo vem sempre ligado ao contexto empresarial e mercadológico, isto é, a sociedade aparece, para esses sujeitos, como sinônimo de mercado.

Em outra questão da entrevista, buscou-se verificar junto aos participantes se, em suas opiniões, o desenvolvimento científico-tecnológico exerce algum tipo de influência sobre a sociedade e quais são as implicações da tecnologia para a ciência e para a sociedade. Nesse sentido, houve unanimidade, isto é, todos os sujeitos disseram que o desenvolvimento da ciência e da tecnologia exerce algum tipo de influência sobre a sociedade. Para alguns dos entrevistados, essa influência reflete nas escolhas das pessoas. Um deles afirma que, "essa influência é garantida por meio do recurso tecnológico aplicado. Por exemplo, se faz o carro elétrico e coloca no mercado, pode uma criança, ao ver, se interessar por aquela área de aprendizado" (informação verbal). Do mesmo modo, isso influencia também nas perspectivas futuras, como complementa o mesmo entrevistado, afirmando que em "outras áreas também cinema, computação gráfica - a tecnologia pode deslumbrar o adolescente ou o pré-adolescente e instigá-lo a aprender como se faz aquele produto, e, assim, garantir um rumo para sua vida" (informação verbal). Outro entrevistado defende que "estamos aí com uma geração que é fortemente influenciada por esse desenvolvimento científico que é a internet, que propicia novos conceitos, novas informações rápidas" (informação verbal). Um terceiro participante afirmou que a tecnologia "muda totalmente" o estilo de vida das pessoas, pois "elas conseguem usufruir de outras possibilidades que nunca tinham pensado. A sociedade foi muito transformada em pouco tempo, hoje a rotina diária é muito mais dinâmica com a tecnologia na vida das pessoas" (informação verbal).

Enfim, vários entrevistados, a exemplo dos mencionados, afirmaram que a tecnologia interfere no cotidiano das pessoas, 
em suas preferências e até em seus interesses pessoais. Para um deles, "o desenvolvimento tecnológico está mudando a sociedade" (informação verbal), no sentido de que os inúmeros aparatos eletrônicos têm propiciado modificações nas formas de trabalho e de convivência, por exemplo; mais explicitamente, como mencionou outro participante: "telefone celular, computador, internet, são coisas que facilitaram a vida e deixaram as pessoas mais próximas, a gente consegue fazer muito mais coisas durante o dia” (informação verbal), podendo inclusive render mais no trabalho. Todavia, apesar de parecer que se está diante de uma visão mais crítica, a influência de que se fala é de apenas uma via. Isto é, nenhum dos participantes chegou a considerar que o inverso também e mais frequentemente ocorra, ou seja, que a sociedade também, com suas demandas, pode influenciar o desenvolvimento científico em uma ou outra direção.

Outro grupo de participantes leva em conta certas reciprocidades na relação entre avanço científico/tecnológico e sociedade. Por exemplo, um entrevistado considera que, se, por um lado, os avanços propiciaram melhorias em várias áreas, por outro, ocasionaram novos problemas. Nesse mesmo viés mais crítico, outro participante considera que "as tecnologias dão acesso à informação, mas não garantem conhecimento". Ou seja, elas podem fornecer muitos dados e parâmetros importantes para o trabalho, mas não "entregam (sic) maturidade para trabalhar" os dados, para "analisar a informação e gerar conhecimento", pois “cabe ao indivíduo julgar o que fazer com a tecnologia e, talvez, nem sempre o indivíduo esteja preparado pra isso" (informação verbal).

Nas entrevistas destes dois participantes, observase que eles reconhecem que o avanço tecnológico suscitou mudanças sociais, e, embora considerem que houve benefícios à sociedade, ao ponderarem os aspectos negativos que o avanço tecnológico pode ocasionar, parecem ter uma visão crítica em relação ao processo de avanço tecnológico. $\mathrm{O}$ último entrevistado citado demonstra um olhar criterioso em relação ao contexto, ao colocar o ser humano acima da 
tecnologia, ou seja, ele limita o poder da tecnologia apenas à função de entregar dados, colocando sobre o homem o papel de controlar esse elemento, julgando que cabe a este analisar, julgar e saber o que deve ser feito com esses dados. Nessa perspectiva, as falas dos entrevistados lembram o pensamento de Pinto (2005) quando este destaca que a técnica é um ato produtivo e é definida como um ato humano; ela, portanto, expressa a relação produtiva do homem com o mundo. Com efeito, "o domínio teórico da técnica pelo homem liberta-o da servidão prática à técnica” (PINTO, 2005, p. 223). Em contrapartida, alguns entrevistados parecem condicionar a "evolução e o avanço" da sociedade ao "avanço científicotecnológico" como um processo linear, em que mais avanço científico implica necessariamente mais avanço social. Por conseguinte, esses sujeitos revelam-se contrários às concepções de autores tais como Kuhn (1989), Garcia, Cerezo e Luján (1996), Bazzo, Linsingen e Pereira (2003) e Silveira (2010), que, em contraposição ao pensamento positivista, discordam que, quanto mais tecnologia se tem, necessariamente mais se obtém soluções.

Outra questão posta aos entrevistados foi o pedido para que dessem suas opiniões sobre ser necessário controlar, colocar limites, e/ou estabelecer critérios em relação ao desenvolvimento de inovações tecnológicas. A esse respeito, houve manifestações distintas quanto aos motivos pelos quais os sujeitos pensam que se deve ou não impor limites na geração de inovações tecnológicas. Alguns respondentes que disseram ser necessário controlar, colocar limites e estabelecer critérios assim o justificaram: "tem, porque tudo isso tem que ser resumido para foco. Procurar focar no que se quer fazer e não abrir muito fora daquilo ali, para poder gerar uma inovação tecnológica de qualidade" (informação verbal). Outro relatou: "sim, é importante colocar alguns limites, porque dependendo da área com que se vai atuar, seu projeto, seu produto, pode acontecer algumas catástrofes, algumas coisas que são relativamente ligadas a algum tipo de inovação que não seja limitante" (informação verbal). Para um terceiro, 
os limites são necessários "por que se tem muita coisa que infringe direitos autorais. [...] tem muitas informações que são privadas, e tem um tipo de recurso chamado mineração de dados, por exemplo, que muitas vezes é usado para coletar informações privadas" (informação verbal). Por outro lado, no entendimento de outros entrevistados, os limites são necessários, porque a sociedade, de alguma forma, não estaria preparada para muitas das "tecnologias" e das "inovações" atuais: "a sociedade como um todo não está pronta para tudo que existe hoje em dia, muitas formas de interação. [...] tudo tem que ter uma curva de aprendizagem" (informação verbal).

Dentre os relatos dos respondentes que relativizaram ou negaram a necessidade de manter controle, colocar limites ou estabelecer critérios em relação ao desenvolvimento de inovações tecnológicas, citamos: "Acho que tudo tem que ter limite no sentido de ver se a ideia é válida, se traz mais benefícios que prejuízos pra sociedade" (informação verbal). Nessa mesma direção, um dos entrevistados afirmou que "deve-se podar, mas no sentido de alertar quando o projeto não é viável” (informação verbal). No entanto, na sequência, ele próprio faz o contraponto: "[...] acredito que, a partir do momento que a incubadora começa a podar muito a ideia do incubado, pode estar dando um tiro do pé, porque dali de dentro pode sair uma ideia que mude algo" (informação verbal). Para outro entrevistado, "depende da área, tem que ter alguém para regular, a norma especifica guia bastante. Então se pode inovar, mas se tem as regras básicas de segurança que foi estabelecida por um comitê" (informação verbal). Um dos participantes afirma que "critérios são importantes, limites nunca"; entretanto, ele também considera que "[...] cumprindo-se as leis e as normas, seguindo os preceitos éticos da sociedade, não há problema, não tem que ter limite" (informação verbal). Este último sujeito parece não ter se dado conta, pois, de que os limites são justamente os "preceitos éticos da sociedade".

O último tópico da entrevista visava identificar, nas falas dos participantes, os modos como estes pensam sobre 
os impactos sociais que suas tecnologias podem causar e se a inovação tecnológica produzida por suas empresas tem ou vai ter contribuição social, e de que tipo. Dentre as repostas, foram identificadas certas visões bastante otimistas, talvez ingênuas, sobre as possibilidades de todos terem acesso aos produtos que fabricam ou que projetam, como se o acesso não dependesse de determinadas condições, inclusive financeiras. Para alguns entrevistados, os impactos sociais têm a ver com o uso dos produtos, os quais, em sua visão, melhoram a vida das pessoas. Um deles, por exemplo, afirmou que seu negócio “já começou com impacto social" (informação verbal), associando tal impacto aos benefícios que seu produto poderá trazer aos usuários, pois "garante mais estrutura para as pessoas com deficiência visual e também mais acessibilidade para quem não tem muito tempo. Garante um alavancamento intelectual, [pois] a pessoa consegue conversar melhor com os membros da equipe e consegue aprender mais profissionalmente, pode garantir uma elevação de salário" (informação verbal). Por sua vez, outro participante defendeu que sua tecnologia impacta a sociedade, porque seu "projeto específico é um modelo novo de fazer um equipamento que já existe" e que, quando sua empresa "mostrar outro jeito de fazer, isso vai espalhar" (informação verbal). Ele argumenta que não se incomoda com uma possível concorrência ao afirmar não ter "problema algum se alguém de outra região vender a mesma coisa, porque será um benefício para as pessoas, é um mercado muito grande. A gente não vai patentear o produto, [pois] o elevador residencial não pode ser patenteado, já é [de] domínio público" (informação verbal).

De maneira geral, os entrevistados, embora digam que seu produto irá contribuir para a melhora da qualidade de vida de seus usuários, sugerindo suas preocupações com as questões sociais, parecem, em realidade, estar fazendo propaganda de seus negócios. Em resumo, eles falam a respeito da funcionalidade do produto desenvolvido por sua empresa, das inovações que proporcionam mudança de rotina ao seu usuário e do atendimento da necessidade do seu consumidor. Essas são proposições defendidas por Schumpeter (1997), Silva (2003) 
e OCDE (2005) sobre o porquê de as empresas inovarem e suscitarem a mudança tecnológica: "a razão apresentada na obra de Schumpeter é que elas estão em busca de lucros: um novo dispositivo tecnológico traz alguma vantagem para o inovador" (OCDE, 2005, p. 33).

Portanto, os entrevistados não deixaram claro o impacto que sua tecnologia poderá causar, no que se refere às diversas dimensões que envolvem o conceito de desenvolvimento, conforme apontam autores críticos como Sachs (2004) e Sen (2010). Isto é, o desenvolvimento é tido como um processo multidimensional em que seus objetivos são sempre sociais, éticos e visam a expansão das liberdades como o principal fim e o principal meio do desenvolvimento.

Outros entrevistados foram bem mais enfáticos e explícitos quanto ao fato de entenderem os impactos sociais de suas tecnologias como inerentes às relações de mercado, isto é, como capazes de corresponder às demandas do mercado. Nesse sentido, afirmou um deles: "ela tem contribuição social porque conseguimos entender o comportamento do consumidor $[. .$.$] , conseguimos, ao mesmo tempo, ajudar$ empresas a fortalecerem suas marcas, estarem presentes na vida do consumidor, e entregar algo que realmente seja útil e proveitoso pra ele" (informação verbal). Outro, por sua vez, aponta o consumidor como alvo da contribuição social de sua tecnologia, ao passo que um terceiro afirma que sua tecnologia "possibilita que as empresas ganhem em competitividade e excelência no que fazem" (informação verbal). Este ainda complementa a afirmação observando que "não tem como todo mundo ter uma $\mathrm{ONG}$, pois alguém teria que pagar a conta. Eu sou empresário, vou fazer ações sociais, é óbvio que eu vou, mas a minha função como empresário é possibilitar que as empresas consigam competir e crescer" (informação verbal). Por fim, ele justifica: "Por quê? Porque eu estou num país capitalista, nós somos capitalistas aqui”.

Enfim, os resultados que obtivemos nas entrevistas nos permitem dizer que os participantes da pesquisa relacionam os impactos sociais das tecnologias com os resultados que estas 
produzirão para o mercado, sobretudo para os consumidores, num viés puramente econômico. Todos citaram os recursos financeiros como promotores do enriquecimento e do desenvolvimento local, questões abrangidas nas propostas do desenvolvimento sobre o aspecto de crescimento econômico, submetido à visão tradicional e hegemônica, conforme esclarecem autores avessos a esse pensamento, como Furtado (1974) e Marini e Silva (2012). Portanto, em seus depoimentos, os entrevistados reforçam o princípio schumpeteriano sobre o desenvolvimento estar traduzido em termos de crescimento econômico, fomentado pelo aumento da produtividade, do faturamento e, consequentemente, da competitividade.

\section{Considerações finais}

$\mathrm{Na}$ pesquisa relatada neste artigo, analisaram-se as concepções acerca de como se dá a relação entre ciência, tecnologia, inovação e desenvolvimento na visão dos gestores e de participantes do Programa de Empreendedorismo e Inovação (Proem) no campus Cornélio Procópio da Universidade Tecnológica Federal do Paraná (UTFPR).

Os resultados que obtivemos indicam uma aproximação das concepções dos participantes da pesquisa com a visão tradicional, ainda que os entrevistados tenham demonstrado, em muitos momentos de suas falas, aparente preocupação com as questões sociais, parecendo conceber o desenvolvimento sob uma visão multidimensional como abarcam os estudos críticos. Dessa maneira, na análise das entrevistas, observouse a presença de elementos do pensamento positivista, com forte influência da teoria schumpeteriana acerca do tema. Pelas concepções dos participantes da pesquisa, foi possível verificar forte aproximação com o modelo de desenvolvimento segundo o qual, na visão schumpeteriana, quanto mais se gera ciência, mais se gera tecnologia, e, quanto mais tecnologia, por consequência, mais se produz riqueza, que, por sua vez, é a base do bem-estar social.

Verificou-se, ainda, que, de maneira geral, para os entrevistados, a sociedade parece traduzir-se pelo mercado, 
pois, ao apontarem sua preocupação com as questões da sociedade, pontuavam questões vinculadas ao contexto mercadológico, próprio da visão do sistema capitalista, pautado pelo atendimento às demandas do consumidor. Dessa forma, os entrevistados reforçam o princípio schumpeteriano sobre o desenvolvimento estar traduzido em termos de crescimento econômico, fomentado pelo aumento da produtividade, do faturamento e, consequentemente, da competitividade.

Por fim, os resultados que obtivemos nos permitem lançar a hipótese de que as concepções identificadas norteiam as práticas profissionais dos participantes, bem como que tais práticas contribuem para o desenvolvimento local e regional numa visão economicista, isto é, em suma, que demonstram os modos como concebem a relação entre ciência, tecnologia, inovação e o desenvolvimento. Assim, espera-se que este trabalho possa contribuir com estudos futuros que por ventura tenham o propósito de refletir sobre as relações analisadas em ambientes de incubação de empresas, ou ainda, em outros espaços sociais relacionados a esta temática.

\section{Referências}

BAZZO, W.; LINSINGEN, I. Von; PEREIRA, L. T. V. (Ed.). Introdução aos estudos CTS (Ciência, Tecnologia e Sociedade). Cadernos de Iberoamérica. Madri: Organização dos Estados Iberoamericanos para a Educação, a Ciência e a Cultura, 2003.

BOURDIEU, P. O Campo Científico. In: ORTIZ, Renato; FERNANDES, Florestan. Pierre Bourdieu: Sociologia. São Paulo: Ática, 1983.

BRASIL. Lei no 10.973/2004, de 02 de novembro de 2004. Dispõe sobre incentivos à inovação e à pesquisa científica e tecnológica no ambiente produtivo e dá outras providências. Diário Oficial da União, , Brasília, DF, 03 dez. 2004. Disponível em: <http://www. planalto.gov.br/ccivil_03/_ato2004-2006/2004/lei/ 110.973.htm>. Acesso em: 11 set. 2015.

BRASIL. Lei no 11.196/2005, de 21 de novembro de 2005. Dispõe sobre incentivos fiscais para a inovação tecnológica. Diário Oficial da União, , Brasília, DF, 22 nov. 2005a. Disponível em: <http:// www.planalto.gov.br/ccivil_03/_ato2004-2006/2005/lei/111196. htm >. Acesso em: 11 set. 2015. 
BRASIL. Lei no 11.184, de 07 de outubro de 2005. Dispõe sobre a transformação do Centro Federal de Educação Tecnológica do Paraná em Universidade Tecnológica Federal do Paraná e dá outras providências. Diário Oficial da União, Brasília, DF, 10 out. 2005b. Disponível em: <http://www.utfpr.edu.br/a-instituicao/ documentos-institucionais/leis-e-decretos/lei-no-11.184-de-07de-outubro-de-2005 >. Acesso em: 15 mai. 2015.

BUSATO, J. A concepção de desenvolvimento da Universidade Tecnológica Federal do Paraná Câmpus Pato Branco. 2012. 164 f. Dissertação (Mestrado em Desenvolvimento Regional)Universidade Tecnológica Federal do Paraná, Pato Branco, 2012.

CALLON, M. Por uma nova abordagem da ciência da inovação e do mercado: o papel das redes sócio-técnicas. In: PARENTE, A (Org.). Porto Alegre: Sulina, 2004.

COSTA, R. V. Introdução. In: SCHUMPETER, Joseph A. Teoria do desenvolvimento econômico: uma investigação sobre lucros, capital, crédito, juro e o ciclo econômico. São Paulo: Nova Cultural, 1997. p. 5-13.

ETZKOWITZ, H. Hélice tríplice: Universidade-IndústriaGoverno: inovação em movimento. Porto Alegre: EDIPUCRS, 2009.

FURTADO, C. O mito do desenvolvimento econômico. São Paulo: Círculo do Livro, 1974.

GONZÁLEZ GARCÍA, M. I., LÓPEZ CEREZO, J.A. y LUJÁN LÓPEZ, J. L. Ciencia, tecnología y sociedad: una introducción al estudio social de la ciencia y la tecnología. Madrid: Technos, 1996.

KUHN, T. S. A estrutura das revoluções científicas. São Paulo: Perspectiva, 1989.

LATOUR, B. Jamais fomos modernos: ensaio de antropologia simétrica. Rio de Janeiro: Ed. 34, 1994.

MARINI, M. J.; SILVA, C. L. Desenvolvimento regional: uma abordagem interdisciplinar. In: LADWIG, N. I.; COSTA, R. S. (Org.). Relações internacionais, gestão do conhecimento e estratégias de desenvolvimento: debates interdisciplinares na primeira década do novo milênio. Palhoça: Ed. Unisul, 2012.

MEDEIROS, J. A. Polos, parques e incubadoras: a busca da modernização e competitividade. Brasília: CNPq: IBICT: SENAI, 1992. 
MINAYO, M. C. S. Pesquisa social: teoria, método e criatividade. 14 ed. Rio de Janeiro: Vozes, 1992.

PINTO, A. V. O Conceito de tecnologia. Rio de Janeiro: Contraponto, 2005.

ORGANIZAÇÃO DE COOPERAÇÃO E DE DESENVOLVIMENTO ECONÔMICO - OCDE. Manual de Oslo. 3. ed. 2005. Disponível em: <http://www.oei.es/salactsi/oslo2. pdf>. Acesso em: 08 set. 2015.

SACHS, I. Desenvolvimento: includente, sustentável, sustentado. Rio de Janeiro: Garamond, 2004.

SANTOS, B. S. A Gramática do tempo: para uma nova cultura política. São Paulo: Cortez, 2006.

SCHUMPETER, J. A. Teoria do desenvolvimento econômico: uma investigação sobre lucros, capital, crédito, juro e o ciclo econômico. São Paulo: Nova Cultural, 1997.

SEN, A. Desenvolvimento como liberdade. São Paulo: Companhia da Letras, 2010.

SILVA, J. C. T. Tecnologia: novas abordagens, conceitos, dimensões e gestão. Revista Produção, v. 13, n. 1, p. 50-63, fev. 2003.

SILVEIRA, R. M. C. F; BAZZO, Walter. Desenvolvimento científico e tecnológico na visão de geradores de tecnologia: resquícios da educação tecnológica. In: Congresso Brasileiro de Educação em Engenharia, XXXVIII COBENGE 2010, FortalezaCE. ABENGE: Fortaleza, 2010.

R. M. C. F.; BAZZO, W. Ciência, tecnologia e suas relações sociais: a percepção de geradores de tecnologia e suas implicações na educação tecnológica. Ciência \& Educação, v. 15, n. 3, p. 681-694, 2009.

TIDD, J.; BESSANT, J.; PAVITT, K. Gestão da Inovação. Porto Alegre: Bookman, 2008.

UNIVERSIDADETECNOLÓGICA FEDERALDO PARANÁ - UTFPR. Regulamento do Programa de Empreendedorismo e Inovação - Proem. Curitiba: UTFPR, 2009.

UNIVERSIDADE TECNOLÓGICA FEDERAL DO PARANÁ - UTFPR. Plano de Desenvolvimento Institucional 2013-2017. Curitiba: UTFPR, 2014. 
UNIVERSIDADETECNOLÓGICAFEDERALDOPARANÁ

Revista Grifos 285

- UTFPR. Apresentação Programa de Empreendedorismo e

Inovação da UTFPR. Curitiba: UTFPR, 2015.

Submetido em: 23/05/2016

Aprovado em: 11/12/2016

\title{
SCIENCE, TECHNOLOGY, INNOVATION AND DEVELOPMENT INTHE UNIVERSITY ENTREPRENEURSHIP PROGRAM TECHNOLOGICAL FEDERAL PARANÁ
}

\begin{abstract}
In Brazil policies have been developed to support technological innovation processes for companies in order to provide the same best conditions to remain healthy in the market and improve their competitive potential. It is in this context that the Program Entrepreneurship and Innovation PROEM, developed at the Federal Technological University of Paraná, Campus Cornélio Procópio - UTFPR-CP. This article results from research that examined the ways in which participants in this program conceive the relationship between science, technology, innovation and development. voluntarily participated in the study 14 subjects between managers graduated companies, incubated companies managers, pre-incubated business managers and UTFPR servers operating in PROEM. Data were collected through semi-structured interview, whose script focused on ways participants conceive relations between science, technology, innovation and development, and conceive the social implications of these relationships. The analysis was done by interpreting the answers given by the subjects in the interviews. The results indicate the presence of elements of positivist thinking. It was possible to verify approximation of the conceptions of the participants with the development model, according to which, the more it generates science, more is generated technology and more technology therefore produces more wealth and social well-being, which, in time is the basis of Schumpeterian theory.
\end{abstract}

Keywords: Science. Technology. Innovation. Development. Entrepreneurship. 